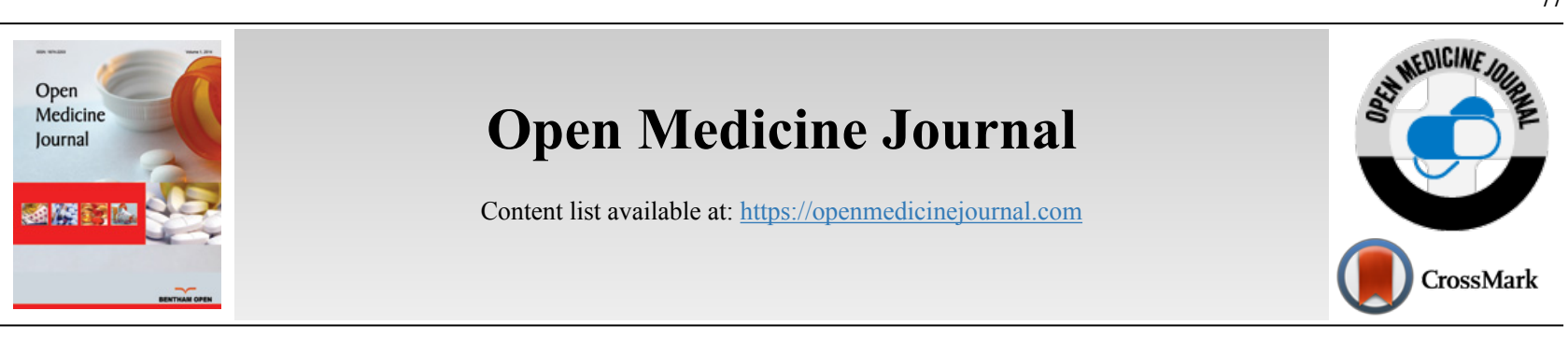

RESEARCH ARTICLE

\title{
Maternal Prenatal Anthropometry, High Education and Cesarean Delivery as Risk Factors for Low Gestational Age in Iran
}

\author{
Sorayya Kheirouri ${ }^{1}$, Mohammad Alizadeh", ${ }^{2, *}$ and Parvin Sarbakhsh ${ }^{3}$ \\ ${ }^{\prime}$ Department of nutrition, Tabriz University of Medical Sciences, Tabriz, Iran \\ ${ }^{2}$ Nutrition research center, Tabriz University of Medical Sciences, Tabriz, Iran \\ ${ }^{3}$ Department of statistics and epidemiology, Tabriz University of Medical Sciences, Tabriz, Iran
}

\begin{abstract}
:
Background:

Preterm birth is an important contributor to the global burden of disease. Evidence indicating that maternal health, nutritional and socioeconomic status may contribute to preterm birth.

Objective:

This cross-sectional study was conducted to describe the contribution of prenatal maternal factors on low gestational age, and to assess newborns anthropometric measurements regarding gestational age.

\section{Methods:}

Data of mothers delivering a singleton live infant $(n=759)$ and their newborns $(n=755)$ during the two years up to August 2014 were collected. Data were collected from the data set of eight public health centers which were chosen from different administrative regions of Tabriz city and were analyzed. Differences between the groups were assessed by Student's t-test or one- way analysis of variance (ANOVA). Multiple linear regression was used to estimate the association between gestational age and variables studied.

Results:

Incidence of preterm birth was $2.1 \%$. Percentage of infants with low birth weight and Head Circumference (HC) under $34 \mathrm{~cm}$ was significantly higher in the preterm group. Mean gestational age was lower in mothers with cesarean delivery, high education, high economic status, high BMI, pre-pregnancy weight $\geq 65 \mathrm{~kg}$ and medical problem. Gestational age was inversely associated with maternal pre-pregnancy weight $\geq 65 \mathrm{~kg}$ (B= $-0.20, \mathrm{p}=0.02)$, high $\mathrm{BMI}(\mathrm{B}=-0.33, \mathrm{p}=0.01)$, high education $(\mathrm{B}=-0.47, \mathrm{p}=0.002)$ and cesarean delivery $(\mathrm{B}=-0.74, \mathrm{p}<0.001)$.

\section{Conclusion:}

The results indicate that maternal anthropometric characteristics, education and type of delivery are associated with gestational age. Explorating potentially modifiable risk factors for unfavorable gestational age and integrating them into intervention efforts may ameliorate adverse birth outcomes.
\end{abstract}

Keywords: Gestational age, Education, Economic status, Gestational weight gain, Age, Anthropometry, Preterm birth.

\begin{tabular}{|l|l|l|l}
\hline Article History & Received: April 13, 2019 & Revised: July 28, 2019 & Accepted: August 20, 2019
\end{tabular}

\section{INTRODUCTION}

Preterm birth is the birth of a baby born alive before 37 weeks of pregnancy completed ${ }^{1}$. Preterm birth is a universal problem and according to estimates, 15 million neonates are born preterm every year and this amount is growing [1]. The

\footnotetext{
"Address correspondence to this author at Nutrition research center, Tabriz University of Medical Sciences, Attar Nishabouri St., Tabriz, I.R. Iran; Postal code: 5166614711; POBOX: 14711, Tel: 0098-41-33362117;

Fax: 0098-41-33340634; E-mail: mdalizadeh@tbzmed.ac.ir
}

complications of preterm birth are major factors accounting for death in children under 5 years, according to the World Health Organization (WHO) report [1], and $28 \%$ of all early neonatal deaths [2]. Preterm birth has lifetime impact on neuro developmental functioning of many survivors, including impaired learning and visual and hearing disorders [3]. In 2010 , rate of preterm birth was estimated $5 \%$ of live births for some developed regions, $18 \%$ for some developing countries such as Malawi and $10.1 \%$ for western Asia including Iran [4]. 
Commonly, the exact cause of premature birth is not clear. Various factors may influence the risk of preterm birth. Major reasons of premature birth include multiple pregnancies [5], amniotic fluid and lower genital tract infections [6], and maternal chronic diseases such as diabetes and high blood pressure [7], maternal pre-pregnancy nutritional status (poor nutrition, being underweight or overweight) [8], stressful life events [9], inadequate interval between pregnancies, smoking, and drinking alcohol [10]. In recent decades, cesarean section delivery before full term has been recognized as another reason for enhancement of preterm birth rates [11].

Besides, there are many unexplained and unknown sociocultural factors involved in preterm birth which needs to be elucidated. Identifying and comprehensively understanding the causes and mechanisms involved in the development of preterm birth will advance implementation of appropriate public health programs and/or policies to decrease the occurrence of preterm birth and prevent its considerable adverse outcomes. According to the previous investigations, maternal health, nutritional and socioeconomic status may contribute to preterm birth $[7,8,12]$. Therefore, this study was aimed (1) to describe contribution of prenatal maternal anthropometric, education, economic status and age on undesirable gestational age and (2) to assess neonates' anthropometric measurements regarding gestational age in Iranian population.

\section{MATERIALS AND METHODS}

\subsection{Field of Study and Participants}

A cross-sectional, mother-infant pairs study was carried out in Tabriz, capital of East Azerbaijan province located in Northwest of Iran. Data included in this study were collected by random sampling from data set of eight primary health care centers which were selected based on high coverage of population from existence administrative regions of the city $(\mathrm{n}=8$, one center from each region), during the two years up to August 2014. As this study did not contain any participation of human subjects, no written human subject consent was necessary. Access to the health records within the centers was facilitated by written permission of provincial health bureau affiliated to Tabriz University of Medical Sciences (reference numbers: 548-550).

Data of 759 urban mothers who gave birth to live infant and their newborns were obtained and included in the analysis. In order to avoid the confusion of multiple deliveries, twin or triplet deliveries were excluded. Information of all maternal and neonatal factors which were speculated to affect gestational age was collected.

Neonates with birth weight less than $2500 \mathrm{~g}$ were defined as Low Birth Weight (LBW) [13] and babies born alive fall into one of the four groups of preterm ( $\leq 36$ weeks), early term (37- 38 weeks), full term (39-40 weeks) and late term ( $\geq 41$ weeks), with respect to gestational age. Regarding age at the time of delivery, mothers were classified into three groups as follows: age $<18,18-34.9$ and $\geq 35$ years given the fact that pregnan-cies under 18 years and over 35 years are accompanied with maternal and neonatal complications and considered as high-risk pregnancy $[14,15]$. Optimal cut-off values of the maternal height, pre-pregnancy weight and infant birth Head Circumfe-rence (HC) were determined using Receiver Operating Charac-teristic curves (ROC) and also from previous studies [16, 17].

Three levels of education were defined for mothers as follows: low education (Illiterate or primary education), moderate education (junior or senior high school level) and high education (college or university). Considering subjects' occupation and education level, three levels of low, middle and high were defined for economic status [18]. Medical problem was defined as having any disease during the gestational period.

\subsection{Statistics}

All analyses were performed using SPSS version 16.0 (IBM SPSS statistics, IL, Chicago, USA). The KolmogorovSmirnov normality test was used to identify the distribution of data. Mean \pm Standard Deviation (SD) was computed for data with normal distribution including infants' birth weight, height, $\mathrm{HC}$, and gestational age. Data with non-normal distribution including gestational weight gain were presented as median (percentile 25,75$)$ and proportional data as frequency (\%). Differences between the groups were assessed by Student's ttest for continuous variables with two categories. For variables with $\geq 3$ categories, differences between groups were assessed by one- way analysis of variance (ANOVA). Multiple linear regression (general linear model) was used to estimate the association between gestational age and maternal factors. Gestational age was used as dependent variable. $\mathrm{P}$ values less than 0.05 were considered statistically significant. Data of 4 neonates were not available, therefore we excluded them and data of 755 neonates were used in the analysis.

\section{RESULTS}

\subsection{Characteristics of Newborns and their Mothers}

Characteristics of the neonates and their mothers are shown in Table 1. Among newborns, only $39.81 \%$ were born full term and $42.64 \%$ of them were first born. Of mothers, $5.1 \%$ were found with medical problems, such as hypertension, diabetes, depression, cardiovascular problems during pregnancy. All mothers were not smoking or drinking.

\subsection{Anthropometric Characteristics of Neonates Regarding Gestational Age}

As shown in Table 2, birth weight, height and HC of infants was significantly lower in preterm neonates (all, $\mathrm{p}<$ 0.001 ) compared to other gestational age groups. Percent of infants with $\mathrm{LBW}$ and $\mathrm{HC}<34$ was significantly higher in preterm group $(\mathrm{p}=0.007$ and $\mathrm{p}=0.02$, respectively).

\subsection{Factors Contributing to Gestational Age}

As shown in Table $\mathbf{3}$, the gestational age was greater in mothers with vaginal delivery than mothers with cesarean delivery $(\mathrm{p}<0.001)$. Gestational age was low in mothers with high education level in comparison to low and moderately educated mothers $(p<0.001)$ (Table 3). Gestational age was low in mothers with high economic status than low economic status ( $p=0.04)$. Mothers with pre-pregnancy weight $\geq 65 \mathrm{~kg}$ had low gestational age than mothers with pre-pregnancy weight $<65 \mathrm{~kg}(\mathrm{p}=0.001)$ (Table 3). Gestational age was low in obese mothers $(\mathrm{BMI} \geq 30)$ compared with normal weight mothers $(p=0.03)$. Gestational age was lower in mothers with 
medical problem during pregnancy compared with mothers without medical problem $(\mathrm{p}=0.001)$. Gestational age did not differ among different mothers' age or height groups (data not shown).

Table 1. Characteristics of the newborn infants and their mothers.

\begin{tabular}{|c|c|}
\hline Newborn weight ${ }^{\mathrm{a}}(\mathrm{kg})$ & $3.20(2.95,3.50)$ \\
\hline Newborn length $^{\mathrm{a}}(\mathrm{cm})$ & $50.00(48.00,51.00)$ \\
\hline Newborn head circumference $^{a}(\mathrm{~cm})$ & $35.00(34.00,35.50)$ \\
\hline Gestational weight gain $^{\mathrm{a}}(\mathrm{kg})$ & $10.52(8.01,13.50)$ \\
\hline $\begin{array}{c}\text { Age }^{\mathrm{b}}(\text { year, } \mathrm{n}=759) \\
<18 \\
18-34.9 \\
\geq 35\end{array}$ & $\begin{array}{c}20(2.60) \\
640(84.40) \\
99(13.00)\end{array}$ \\
\hline $\begin{array}{c}\text { Education }^{\mathrm{b}}(\mathrm{n}=759) \\
\text { low } \\
\text { moderate } \\
\text { high }\end{array}$ & $\begin{array}{l}185(24.40) \\
486(64.00) \\
88(11.60)\end{array}$ \\
\hline $\begin{array}{c}\text { Economic status }^{\mathrm{b}}(\mathrm{n}=754) \\
\text { low } \\
\text { moderate } \\
\text { high }\end{array}$ & $\begin{array}{l}271(35.90) \\
374(49.60) \\
109(14.50)\end{array}$ \\
\hline $\begin{array}{c}\text { Gestational age }^{\mathrm{b}}(\mathrm{n}=759) \\
\text { preterm } \\
\text { early term } \\
\text { full term } \\
\text { late term }\end{array}$ & $\begin{array}{c}16(2.11) \\
424(55.90) \\
302(39.81) \\
17(2.20)\end{array}$ \\
\hline 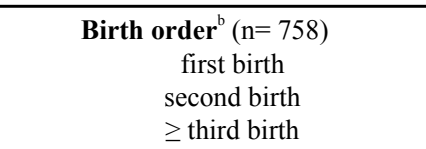 & $\begin{array}{l}326(43.00) \\
316(41.70) \\
116(15.30)\end{array}$ \\
\hline $\begin{array}{c}\text { Medical problem }(\mathrm{n}=585) \\
\text { Yes } \\
\text { No }\end{array}$ & $\begin{array}{c}30(5.11) \\
555(94.90)\end{array}$ \\
\hline
\end{tabular}

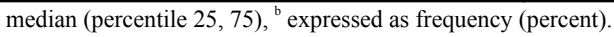

Table 2. Anthropometric characteristics of neonates $(n=$ 755) regarding gestational age.

\begin{tabular}{|c|c|c|c|c|c|}
\hline - & $\begin{array}{c}\text { Preterm } \\
(n=16)\end{array}$ & $\begin{array}{c}\text { Early } \\
\text { Term } \\
(\mathrm{n}=\mathbf{4 2 2})\end{array}$ & $\begin{array}{c}\text { Full Term } \\
(n=301)\end{array}$ & $\begin{array}{c}\text { Late } \\
\text { Term } \\
(n=16)\end{array}$ & p-value \\
\hline $\begin{array}{l}\text { Birth } \\
\text { weight } \\
(\mathrm{kg})^{\mathrm{a}}\end{array}$ & $2.72 \pm 0.56$ & $3.16 \pm 0.47$ & $3.28 \pm 0.43$ & $\begin{array}{c}3.38 \pm \\
0.43\end{array}$ & $<0.001$ \\
\hline \begin{tabular}{|l|}
$\begin{array}{l}\text { Height } \\
(\mathrm{cm})^{\mathrm{a}}\end{array}$ \\
\end{tabular} & $\begin{array}{c}47.47 \pm \\
3.69 \\
\end{array}$ & $\begin{array}{c}49.31 \pm \\
2.41 \\
\end{array}$ & $\begin{array}{c}49.82 \pm \\
2.46 \\
\end{array}$ & $\begin{array}{c}50.37 \pm \\
1.75 \\
\end{array}$ & $<0.001$ \\
\hline $\mathbf{H C}(\mathrm{cm})^{\mathrm{a}}$ & $\begin{array}{c}32.70 \pm \\
2.75\end{array}$ & $\begin{array}{c}34.56 \pm \\
1.51\end{array}$ & $\begin{array}{c}34.67 \pm \\
1.53\end{array}$ & $\begin{array}{c}35.00 \pm \\
1.28\end{array}$ & $<0.001$ \\
\hline $\mathbf{L B W}^{\mathrm{b}}$ & $3(18.8)$ & $26(6.2)$ & $10(3.3)$ & $0(0)$ & 0.007 \\
\hline $\mathrm{HC}<34^{\mathrm{b}}$ & $9(56.3)$ & $87(20.6)$ & $55(18.3)$ & $2(12.5)$ & 0.02 \\
\hline
\end{tabular}

presented as mean \pm SD and analyzed by One-Way ANOVA test, ${ }^{\text {b presented as }}$ frequency (percent) and analyzed by chi-square test.

$\mathrm{LBW}=$ low birth weight; $\mathrm{HC}=$ head circumference.

\subsection{Association of Gestational Age with Maternal Factors}

As shown in Table 4, an inverse association was observed between gestational age with maternal pre-pregnancy weight $\geq$ $65 \mathrm{~kg}(\mathrm{~B}=-0.20, \mathrm{p}=0.02)$, overweight $(\mathrm{B}=-0.25, \mathrm{p}=0.02)$ and obesity $(\mathrm{B}=-0.33, \mathrm{p}=0.01)$, high education $(\mathrm{B}=-0.47, \mathrm{p}=$ $0.002)$ and cesarean delivery $(B=-0.74, p<0.001)$. Gestational age did not correlate with maternal height, age and economic status.

Table 3. Factors contributing to gestational age $(n=759)$.

\begin{tabular}{|c|c|c|}
\hline- & Mean Gestational Age (weeks) & $\mathbf{p}^{\mathbf{a}}$ \\
\hline $\begin{array}{l}\text { Type of delivery } \\
\text { Cesarean }(n=405) \\
\text { Vaginal }(n=318)\end{array}$ & $\begin{array}{l}37.85 \pm 1.15 \\
38.64 \pm 1.09\end{array}$ & $<0.001$ \\
\hline $\begin{array}{l}\text { Education } \\
\text { Low }(n=185) \\
\text { Moderate }(n=486) \\
\text { High }(n=88)\end{array}$ & $\begin{array}{l}38.36 \pm 1.31 \\
38.24 \pm 1.16 \\
37.68 \pm 1.56\end{array}$ & $<0.001$ \\
\hline $\begin{array}{l}\text { Economic status } \\
\quad \text { Low }(n=271) \\
\text { Moderate }(n=374) \\
\text { High }(n=109)\end{array}$ & $\begin{array}{l}38.33 \pm 1.45 \\
38.17 \pm 1.16 \\
37.99 \pm 1.09\end{array}$ & 0.04 \\
\hline $\begin{array}{l}\text { Pre-pregnancy weight }(\mathbf{k g}) \\
\quad<65(\mathrm{n}=418) \\
\geq 65(\mathrm{n}=327)\end{array}$ & $\begin{array}{l}38.34 \pm 1.22 \\
38.03 \pm 1.30\end{array}$ & 0.001 \\
\hline $\begin{array}{l}\text { Mother BMI } \\
\quad<18.5(\mathrm{n}=27) \\
18.5-24.99(\mathrm{n}=309) \\
25-29.99(\mathrm{n}=248) \\
\geq 30(\mathrm{n}=118)\end{array}$ & $\begin{array}{l}38.26 \pm 0.99 \\
38.31 \pm 1.10 \\
38.06 \pm 1.22 \\
37.98 \pm 1.56\end{array}$ & 0.03 \\
\hline $\begin{array}{l}\text { Medical problem } \\
\text { Yes }(n=30) \\
\text { No }(n=555)\end{array}$ & $\begin{array}{l}37.60 \pm 0.77 \\
38.12 \pm 1.02\end{array}$ & 0.001 \\
\hline
\end{tabular}

${ }^{a}$ Differences between groups were assessed by ANOVA for variables with three or more categories and an independent t-student test for variables with two categories.

Table 4. Association of maternal factors with gestational age.

\begin{tabular}{|l|c|c|}
\hline \multicolumn{1}{|c|}{-} & B (95\% CI) & p \\
\hline $\begin{array}{l}\text { Mothers age (year) } \\
<18\end{array}$ & $0.18(-0.36,0.72)$ & 0.51 \\
$18-34.9$ & - & \\
$\geq 35$ & $-0.14(-0.39,0.12)$ & 0.30 \\
\hline $\begin{array}{l}\text { Mother height }(\mathrm{cm}) \\
\quad<160\end{array}$ & $-0.01(-0.18,0.17)$ & 0.92 \\
$\quad \begin{array}{c}160-169.9 \\
\geq 170\end{array}$ & $0.06(-0.28,0.40)$ & 0.73 \\
\hline $\begin{array}{l}\text { Pre-pregnancy weight }(\mathrm{kg}) \\
\quad 655 \\
\geq 65\end{array}$ & - & \\
\hline $\begin{array}{l}\text { Mother BMI }\left(\mathrm{kg} / \mathrm{m}^{2}\right) \\
<18.5\end{array}$ & $-0.20(-0.38,-0.03)$ & 0.02 \\
$\begin{array}{l}18.5-24.99 \\
25-29.99 \\
\geq 30\end{array}$ & $-0.05(-0.53,0.43)$ & 0.83 \\
\hline $\begin{array}{l}\text { Education } \\
\text { low } \\
\text { moderate } \\
\text { high }\end{array}$ & $-0.25(-0.45,-0.04)$ & 0.02 \\
\hline $\begin{array}{l}\text { Economic status } \\
\text { low } \\
\text { moderate } \\
\text { high }\end{array}$ & $-0.33(-0.59,-0.07)$ & 0.01 \\
\hline $\begin{array}{l}\text { Mode of delivery } \\
\text { Cesarean } \\
\text { Vaginal }\end{array}$ & $0.02(-0.20,0.24)$ & 0.85 \\
\hline
\end{tabular}

The univariate general linear model was used for the analysis. Gestational age was used as a dependent variable. 


\section{DISCUSSION}

The results of the present study indicate that maternal anthropometric status, type of delivery and high education are associated with gestational age. Gestational age was inversely associated with maternal pre-pregnancy weight $\geq 65 \mathrm{~kg}$ and BMI. The findings are in agreement with earlier studies linking pre-pregnancy obesity with an elevated risk of preterm birth [8, 19 - 23]. Parker et al. reported that pre-pregnancy obesity is associated with higher risk of preterm birth [8]. McDonald et $a l$. in a systematic review of 84 studies showed that maternal pre-pregnancy obesity is related to a 1.24-fold higher risk of preterm birth [19]. Smith et al. in a cohort study of 187290 women demonstrated that the risk of an elective preterm delivery increased with enhancement of BMI [20]. Cnattingius et al. in a cohort study of 1,599,551 deliveries suggested that maternal overweight and obesity are associated with increased risks of preterm delivery [23]. In the most previous investigations, the association between maternal obesity and preterm birth has been attributed in part to common comorbidities of obesity (hypertensive disorders and gestational diabetes) during pregnancy that are also linked with medicallyinduced preterm birth. In the present study, total number of women with medical problem was 30 (5.1\%) people, and none of them had preterm delivery. Therefore, contribution of preterm delivery to medical conditions of obese women will be of debate due to a smaller number of women with medical problem.

Our study showed that cesarean delivery has the strongest association with premature births. In agreement with the finding, cesarean delivery has previously been implicated as a potential driver involved in increased preterm birth rate [11, 24]. Chang et al. in a study on 39 very high human development index countries found cesarean delivery as an important driver of preterm birth, particularly in the United States [11]. VanderWeele et al. reported that along with the rising trend of preterm births from 1989-2004, the rate of medically induced deliveries increased 94\% [24]. Bond et al. in a meta-analysis study including 12 trials involving 3617 women found that premature birth was associated with an increased rate of cesarean section [25]. Barros et al. in a study 2,903,716 hospital-delivered singletons also showed that low gestational age was associated with high cesarean section rate [26].

Of interest, in the current work, gestational age was adversely associated with maternal high education. In mothers with high education, the number of pregnancy weeks was lower. The result is in-consistent with observed evidence in a recent Brazilian study. Analysis of a national database of over 2.9 million mothers and singleton newborns in Brazil showed that low gestational age was considerably more common among high educated women $(39.8 \%)$ compared with those who had less schooling (24.9\%) [26]. However, several other countries obtained opposite findings. Morgen et al. in a study on 75890 singleton pregnancies have reported that mothers with less than 10 years of education had an increased risk of preterm birth compared with those of more than 12 years of education [27]. Jansen et al. in a cohort study have found that pregnant women with low education had a nearly twofold higher risk of preterm birth than women with high education
[28]. Low education was also determined as a risk factor for preterm birth in a study done by Heaman et al. [29].

Although the exact reasons for high premature birth rate among women with high education are not clear, it is proposed that expansion of obstetric interventions, particularly prelabour cesarean section might be contributed to the high rate of premature birth in this group of population. Barros et al. showed that the prevalence of cesarean section was nearly $80 \%$ in high educated women, and $62 \%$ of these procedures were carried out before labour initiated [26]. Conducting a large part of cesarean section procedures before the onset of labour, indicates that iatrogenic premature births might arise. Besides, the most scheduled cesarean section operations are performed on highly educated women who deliver in private health settings. Leal et al. showed that elective cesarean section had obviously higher rates in private $(61 \%)$ than in public hospitals $(32 \%)$ [30]. Inaccurate estimation of gestational age in the private health services might influence the prevalence of premature births. In the recent decades, elective cesarean section has extremely propagated among Iranian women, more specially among women with high education and economic status $[31,32]$. High cesarean delivery rate among highly educated mothers [75\% (63 of 84 mothers), data not shown] and dropped number of pregnancy weeks in mothers with cesarean delivery in present study further support the idea.

In the present study, the chance of having preterm or early term labor was independent of mothers' economic condition, in high educated mothers. Generally, high education results in high income which may improve health status both at individual, household or community level. However, the association between education and health outcomes via income varies by country. According to previous researches, the relationship between education and health outcomes such as obesity, diabetes, hypertension, etc. is deeply connected to developmental level of the country such that negative associations are more common in high income countries and direct associations are more common in low income countries [33 - 35]. A study in China indicated that, regardless of educational level, the prevalence of diabetes was higher in the high-income group [36]. Also, Monteiro et al. found that high education did not possess any impact on the risk of obesity in the less developed region of the Brazil, but slightly reduced in the more developed regions [35]. Min et al. could not find any strong compensating effect between education and income in patients with diabetes and hypertension [37]. Zimmerman et al. [38] indicated that educational outcomes themselves are conditioned on the many social and environmental contexts and interact with other sociocultural factors and in particular person's individual endowments and experiences. Thus, understanding factors involved in causal pathways between maternal education and negative health outcomes, in particular preterm birth, will be of help to identify targets for intervention.

\subsection{Implication of the Study}

The clarification of risk factors for preterm birth is of great public health importance given its extreme impact on infant growth and health. Our findings suggest another area for public 
health policy makers for the prevention of preterm birth. Surveillance for preterm birth should be considered for women with high weight and high education. High weight women need to receive pre-pregnancy nutrition education interventions to optimize their anthropometric condition. As maternal high educational level may be the strongest predictor of preterm birth in our target population, against many other countries, further investigation on women with high education can be conducted to confirm the risks they are facing. Therefore, more population-based studies are required to identify factors along the causal pathway.

\subsection{Limitations of the Study}

The study was limited by lack of optimal cut-off values for maternal height, pre-pregnancy weight and infants' birth $\mathrm{HC}$ at the national level for Iranian population. Sampling method and source of data may act as impossible biases which may influence the data.

\section{CONCLUSION}

The results indicate that maternal anthropometric characteristics, education and type of delivery are associated with gestational age. Exploring potentially modifiable risk factors for unfavorable gestational age and integrating them into intervention efforts may ameliorate adverse birth outcomes.

\section{ETHICS APPROVAL AND CONSENT TO PARTICIPATE}

Written permission was obtained from provincial health bureau affiliated to Tabriz University of Medical Sciences (reference numbers: 548-550).

\section{HUMAN AND ANIMAL RIGHTS}

No animals/humans were used for studies that are the basis of this research.

\section{CONSENT FOR PUBLICATION}

Not applicable.

\section{AVAILABILITY OF DATA AND MATERIALS}

The authors confirm that data supporting the findings of this research are available within the article.

\section{FUNDING}

None.

\section{CONFLICT OF INTEREST}

The authors declare no conflict of interest, financial or otherwise.

\section{ACKNOWLEDGEMENTS}

Declared none.

\section{REFERENCES}

[1] World Health Organization, preterm birth 2018, Available at: www.who.int/mediacentre/factsheets/fs363/en/ [Accessed 8 March
2019].

[2] Lawn JE, Wilczynska-Ketende K, Cousens SN. Estimating the causes of 4 million neonatal deaths in the year 2000. Int J Epidemiol 2006; 35(3): 706-18.

[http://dx.doi.org/10.1093/ije/dyl043] [PMID: 16556647]

[3] Mwaniki MK, Atieno M, Lawn JE, Newton CR. Long-term neurodevelopmental outcomes after intrauterine and neonatal insults: A systematic review. Lancet 2012; 379(9814): 445-52. [http://dx.doi.org/10.1016/S0140-6736(11)61577-8]

[PMID: 22244654]

[4] Blencowe H, Cousens S, Oestergaard MZ, et al. National, regional, and worldwide estimates of preterm birth rates in the year 2010 with time trends since 1990 for selected countries: A systematic analysis and implications. Lancet 2012; 379(9832): 2162-72.

[http://dx.doi.org/10.1016/S0140-6736(12)60820-4]

[PMID: 22682464]

[5] Kurdi AM, Mesleh RA, Al-Hakeem MM, Khashoggi TY, Khalifa HM Multiple pregnancy and preterm labor. Saudi Med J 2004; 25(5): 632-7.

[PMID: 15138532]

[6] Ovalle A, Martínez MA, Gómez R, et al. Premature labor with intact membranes: Microbiology of the amniotic fluid and lower genital tract and its relation with maternal and neonatal outcome. Rev Med Chil 2000; 128(9): 985-95.

[PMID: 11349503]

[7] Werder E, Mendola P. Effect of maternal chronic disease on obstetric complications in twin pregnancies in a United States cohort. Fertil Steril 2013; 100(1): 142-9.

[8] Parker MG, Ouyang F, Pearson C, et al. Prepregnancy body mass index and risk of preterm birth: Association heterogeneity by preterm subgroups. BMC Pregnancy Childbirth 2014; 14: 153.

[http://dx.doi.org/10.1186/1471-2393-14-153] [PMID: 24779674]

[9] Latendresse G. The interaction between chronic stress and pregnancy: Preterm birth from a biobehavioral perspective. J Midwifery Womens Health 2009; 54(1): 8-17.

[http://dx.doi.org/10.1016/j.jmwh.2008.08.001] [PMID: 19114234]

[10] Parazzini F, Chatenoud L, Surace M, et al. Moderate alcohol drinking and risk of preterm birth. Eur J Clin Nutr 2003; 57(10): 1345-9. [http://dx.doi.org/10.1038/sj.ejen.1601690] [PMID: 14506499]

[11] Chang HH, Larson J, Blencowe $\mathrm{H}$, et al. Born Too Soon preterm prevention analysis group. Preventing preterm births: Analysis of trends and potential reductions with interventions in 39 countries with very high human development index. Lancet 2013; 381(9862): 223-34. [http://dx.doi.org/10.1016/S0140-6736(12)61856-X] [PMID: 23158883]

[12] Whitehead NS. The relationship of socioeconomic status to preterm contractions and preterm delivery. Matern Child Health J 2012; 16(8): 1645-56.

[http://dx.doi.org/10.1007/s10995-012-0948-4] [PMID: 22311578]

[13] World Health Organization, Nutrition, Global Nutrition Targets 2025: Low birth weight policy brief. Available at: https://www.who. int/nutrition/publications/globaltargets2025_policybrief_lbw/en [Accessed 15 April 2019].

[14] Najati N, Gojazadeh M. Maternal and neonatal complications in mothers aged under 18 years. Patient Prefer Adherence 2010; 4: 219-22.

[http://dx.doi.org/10.2147/PPA.S11232] [PMID: 20694181]

[15] Lampinen R, Vehviläinen-Julkunen K, Kankkunen P. A review of pregnancy in women over 35 years of age. Open Nurs J 2009; 3: 33-8. [http://dx.doi.org/10.2174/1874434600903010033] [PMID: 19707520]

[16] Kheirouri S, Alizadeh M. Impact of prenatal maternal factors and birth order on the anthropometric status of newborns in Iran. J Biosoc Sci 2016; 25 : 1-14.

[PMID: 27453129]

[17] Rashidi AA, Kiani O, Heidarzadeh M, et al. Reference curves of birth weight, length, and head circumference for gestational age in iranian singleton births. Iran J Pediatr 2018; 28(5)e66291

[http://dx.doi.org/10.5812/ijp.66291]

[18] Kheirouri S, Alizadeh M. The contribution of prenatal maternal factors to maternal gestational weight gain. Health Care Women Int 2017; 38(6): 544-55.

[http://dx.doi.org/10.1080/07399332.2017.1279163]

[PMID: 28071985]

[19] McDonald SD, Han Z, Mulla S, Beyene J. Knowledge Synthesis Group. Overweight and obesity in mothers and risk of preterm birth and low birth weight infants: Systematic review and meta-analyses. BMJ 2010; 341: c3428. 
[http://dx.doi.org/10.1136/bmj.c3428] [PMID: 20647282]

[20] Smith GC, Shah I, Pell JP, Crossley JA, Dobbie R. Maternal obesity in early pregnancy and risk of spontaneous and elective preterm deliveries: A retrospective cohort study. Am J Public Health 2007; 97(1): 157-62

[http://dx.doi.org/10.2105/AJPH.2005.074294] [PMID: 17138924]

[21] Rudra CB, Frederick IO, Williams MA. Pre-pregnancy body mass index and weight gain during pregnancy in relation to preterm delivery subtypes. Acta Obstet Gynecol Scand 2008; 87(5): 510-7.

[http://dx.doi.org/10.1080/00016340801996838] [PMID: 18446533]

[22] Wise LA, Palmer JR, Heffner LJ, Rosenberg L. Prepregnancy body size, gestational weight gain, and risk of preterm birth in AfricanAmerican women. Epidemiology 2010; 21(2): 243-52.

[http://dx.doi.org/10.1097/EDE.0b013e3181cb61a9]

[PMID: 20124904]

[23] Cnattingius S, Villamor E, Johansson S, et al. Maternal obesity and risk of preterm delivery. JAMA 2013; 309(22): 2362-70.

[http://dx.doi.org/10.1001/jama.2013.6295] [PMID: 23757084]

[24] VanderWeele TJ, Lantos JD, Lauderdale DS. Rising preterm birth rates, 1989-2004: Changing demographics or changing obstetric practice? Soc Sci Med 2012; 74(2): 196-201.

[http://dx.doi.org/10.1016/j.socscimed.2011.10.031] [PMID: 22177849]

[25] Bond DM, Middleton P, Levett KM, et al. Planned early birth versus expectant management for women with preterm prelabour rupture of membranes prior to 37 weeks' gestation for improving pregnancy outcome. Cochrane Database Syst Rev 2017; 3CD004735. [http://dx.doi.org/10.1002/14651858.CD004735.pub4] 28257562]

[26] Barros FC, Rabello Neto DL, Villar J, et al. Caesarean sections and the prevalence of preterm and early-term births in Brazil: Secondary analyses of national birth registration. BMJ Open 2018; 8(8)e 021538. [http://dx.doi.org/10.1136/bmjopen-2018-021538] [PMID: 30082353]

[27] Morgen CS, Bjørk C, Andersen PK, Mortensen LH, Nybo Andersen AM. Socioeconomic position and the risk of preterm birth-a study within the Danish National Birth Cohort. Int J Epidemiol 2008; 37(5): 1109-20.

[http://dx.doi.org/10.1093/ije/dyn112] [PMID: 18577529]

[28] Jansen PW, Tiemeier H, Jaddoe VW, et al. Explaining educational inequalities in preterm birth: The generation $\mathrm{r}$ study. Arch Dis Child Fetal Neonatal Ed 2009; 94(1): F28-34. [http://dx.doi.org/10.1136/adc.2007.136945] [PMID: 18562446]

29] Heaman M, Kingston D, Chalmers B, Sauve R, Lee L, Young D. Risk factors for preterm birth and small-for-gestational-age births among Canadian women. Paediatr Perinat Epidemiol 2013; 27(1): 54-61. [http://dx.doi.org/10.1111/ppe.12016] [PMID: 23215712]

[30] Leal MdoC, Esteves-Pereira AP, Nakamura-Pereira M, et al. Providerinitiated late preterm births in Brazil: Differences between public and private health services. PLoS One 2016; 11(5: )e0155511.

[http://dx.doi.org/10.1371/journal.pone.0155511] [PMID: 27196102]

[31] Yazdizadeh B, Nedjat S, Mohammad K, Rashidian A, Changizi N, Majdzadeh R. Cesarean section rate in Iran, multidimensional approaches for behavioral change of providers: A qualitative study. BMC Health Serv Res 2011; 11: 159.

[http://dx.doi.org/10.1186/1472-6963-11-159] [PMID: 21729279]

[32] Rafiei M, Saei Ghare M, Akbari M, et al. Prevalence, causes, and complications of cesarean delivery in Iran: A systematic review and meta-analysis. Int J Reprod Biomed (Yazd) 2018; 16(4): 221-34. [http://dx.doi.org/10.29252/ijrm.16.4.221] [PMID: 29942930]

[33] McLaren L. Socioeconomic status and obesity. Epidemiol Rev 2007; 29: 29-48.

[http://dx.doi.org/10.1093/epirev/mxm001] [PMID: 17478442]

[34] Cohen AK, Rai M, Rehkopf DH, Abrams B. Educational attainment and obesity: A systematic review. Obes Rev 2013; 14(12): 989-1005. [http://dx.doi.org/10.1111/obr.12062] [PMID: 23889851]

[35] Monteiro CA, Conde WL, Popkin BM. Independent effects of income and education on the risk of obesity in the Brazilian adult population. $\mathrm{J}$ Nutr 2001; 131(3): 881S-6S.

[http://dx.doi.org/10.1093/jn/131.3.881S] [PMID: 11238779]

[36] Hu D, Sun L, Fu P, et al. Prevalence and risk factors for type 2 diabetes mellitus in the Chinese adult population: The InterASIA Study. Diabetes Res Clin Pract 2009; 84(3): 288-95.

[http://dx.doi.org/10.1016/j.diabres.2009.02.021] [PMID: 19442859]

[37] Min H, Chang J, Balkrishnan R. Sociodemographic risk factors of diabetes and hypertension prevalence in republic of Korea. Int $\mathrm{J}$ Hypertens 2010; 2010410794

[http://dx.doi.org/10.4061/2010/410794] [PMID: 20948560]

[38] Zimmerman E, Woolf SH. Understanding the Relationship Between Education and Health. 2014, Discussion Paper, Institute of Medicine, Washington, DC. Available at: http://nam.edu/wp-content/uploads /2015/06//understandingtherelationship [http://dx.doi.org/10.31478/201406a]

\section{C) 2019 Kheirouri et al.}

This is an open access article distributed under the terms of the Creative Commons Attribution 4.0 International Public License (CC-BY 4.0), a copy of which is available at: (https://creativecommons.org/licenses/by/4.0/legalcode). This license permits unrestricted use, distribution, and reproduction in any medium, provided the original author and source are credited. 